\title{
Urban Agriculture and Campus Sustainability: Recent Books
}

Stephanie Ritchie

\begin{abstract}
Food and agriculture meet an essential need of all humans and the details of how food is produced, distributed, consumed, and disposed is of increasing interest (Hedegaard Larsen, 2016). To meet the growing expectations of the campus community, many college and university decision-makers are including food and agriculture concerns as part of curricula, and in the planning, development, and sustainability efforts. This selected bibliography includes a selection of recently published books covering issues relevant to institutions of higher education on food, agriculture, and sustainability efforts.
\end{abstract}

\section{Keywords}

Urban farming, Student farms, Sustainability, Higher education, Food systems

\section{Introduction}

This bibliography brings together books that discuss food and agriculture activities, either on campuses or in urban settings, to inform food and agricultural work on urban campuses. Books selected cover farming activities in urban settings, and perspectives from administrators, educators, public officials, and others that share challenges of determining how best to integrate food production and other sustainability activities to successfully meet goals and expectations. Together, this collection provides a broad overview of food and agriculture topics likely to be of most importance in an urban campus setting.

This collection is organized into topic areas that cover urban agriculture, designing spaces for agriculture, and agriculture as part of greater sustainability efforts. Each of the books included were published within the past five years, and provide background and deeper exploration of urban agriculture concepts for a reader interested in a comprehensive look at each specific topic.

\section{Urban Agriculture}

Urban agriculture, at its most basic, is defined as the production of food (and other agricultural products) within a city. The books included in this section specifically focus of food production activities and the local food systems that encompass our urban areas.

Ladner, P. (2011). The urban food revolution: Changing the way we feed cities. Gabriola Island, B.C.: New Society Publishers. xi, 291 pgs.: illustrations, map. ISBN: 9780865716834

Primarily written for public officials and planners, The urban food revolution: Changing the way we feed cities covers the landscape of urban agriculture through a series of chapters that examine 
the broad range of interrelated issues among food production, urban planning and public health. Although intended to provide advice to decision-makers about what they can do to improve access to healthy food for their constituents, this book is particularly useful to those readers with no prior knowledge of food systems literature.

Using site visits and interviews with urban agriculture projects across the United States and Canada, Ladner characterizes success for proven and emerging urban agriculture strategies. The introductory chapters summarize the most pressing challenges of the current food system. Later chapters focus on innovation that campus decision makers may find helpful as they plan campus food system and sustainability efforts. To conclude the book, Ladner offers solutions that have worked at various levels of government including city and local levels that are likely to be similar and tied to campus-level food system decisions. These recommendations are particularly useful as Peter Ladner brings a wealth of knowledge about community-level urban agriculture from his years spent serving as a Vancouver City Councilor (2002-08). There, he worked with the Vancouver Food Policy Council, and as a Fellow at Simon Fraser University Centre for Dialogue, researching and educating on the theme "Planning Cities as if Food Matters." Here, he has deftly translated the ideas and academic research from the food and agriculture policy realm into an easily understood summary for each of the topics covered. Additional sources of information are found in extensive references and notes for each chapter.

Supplemental Information

Urban Food Revolution Blog from Peter Ladner: http://www.urbanfoodrevolution.com/ Urban Food Revolution Presentation: https://www.youtube.com/watch?v=UGxakDsbxAk Food Talks Vancouver with Peter Ladner: https://www.youtube.com/watch?v=7IiDPLa5Ivc

Reynolds, K., \& Cohen, N. (2016). Beyond the kale: Urban agriculture and social justice activism in New York City. Athens, GA: University of Georgia Press. 189 p. ISBN: 9780820349503

The purpose of urban agriculture often reaches beyond food production, to become a tool to create social and environmental change. From this perspective, urban agriculture is not only the food produced, but the socioeconomic, political, environmental, and other social actions that intertwine with the act of food production to impact individual producers, consumers, and communities. Urban farms may be understood as tools to resist food insecurity, or spaces to reconnect to nature; they may be "safe spaces" for the oppressed, or places for the community to connect. These spaces, and the activities held within those spaces, impact food systems, as well as community development, community building, and community preservation work.

Through the lens of New York City, Reynolds and Cohen observe urban agriculture and its place in social justice movements. They provide a framework for analysis which includes critical race theory, theories of intersectionality and oppression, ideas about social justice work, and research and writing to support activism. They use interviews with people of color and other activists who do not resemble the white, middle-class couples often portrayed as the face of urban agriculture in media, to illustrate and embody themes across urban agricultural activism. 
Reynolds and Cohen acknowledge that this book is an activist effort, while also recognizing their positions of privilege as "white, upper middle class academics" at Yale University/The New School and City University of New York, respectively. Their intention is to address a broader lack of significant discourse about injustices in urban agriculture and food systems. They hope that future discussions will include the voices of people of color and other marginalized groups.

For administrators, staff, and faculty on campuses, the understanding that efforts to create, expand, promote or otherwise encourage urban agriculture may also indicate a social justice mission on the part of student and community activists, could be necessary to successfully support these projects. An urban agriculture project is not always just about food. Beyond the Kale offers clues to making urban agriculture projects inclusive, socially just, and transformative. More information about exemplary farms and projects highlighted in this book is available in the appendices as models for socially active urban agriculture projects.

Supplemental Information

Beyond the Kale Project: https://beyondthekale.org/

Urban Food Policy Forum: Beyond the Kale:

http://www.cunyurbanfoodpolicy.org/events/2016/9/15/urban-food-policy-forum-beyond-thekale-urban-agriculture-and-social-justice-activism-in-new-york-city

Beyond the Kale: Preliminary Findings Video:

https://www.youtube.com/watch?v=2I5ID3HpbuY

Cockrall-King, J. (2012). Food and the city: Urban agriculture and the new food revolution. Amherst, NY: Prometheus Books. 372 p.: illustrations. ISBN: 9781616144586

Food and the city: Urban agriculture and the new food revolution opens with several chapters that cover the history and current state of supermarkets, the conventional/industrial food chain, and the role of the "eaters" in the food system including humans (consuming food), animals (consuming feed) and machines (consuming fuel). These introductory chapters are capped off by an examination of several crises' that face agriculture-from climate change to reaching the "peak" of several natural resources.

In contrast, urban agriculture is introduced as a panacea for all the failures of the industrial food system. A brief history of what Cockrall-King terms the "new food movement" from the 1990s to today prefaces a series of chapters that tour various locales in Europe and North America to detail the history and current work in urban agriculture. Cities profiled include Paris, London, Los Angeles, Vancouver, Toronto, Milwaukee, Detroit, and several in Cuba. Cockrall-King visited urban farms, gardens, allotments, balconies, and many other creative models of using urban space to grow food. She includes photos and interviews with individual growers, as well as information about the political and cultural setting these gardens exist within. These profiles will be of particular interest to those located in these cities or cities with similar characteristics.

Jennifer Cockrall-King is a Canadian food journalist, and as such, primarily uses this book to tell a story about the beneficial potential of urban agriculture. Her passion for the subject is apparent, but no critical analysis of the proposed benefits is covered. A bibliography, chapter notes, references for further information on urban agriculture and a short glossary for concepts covered 
in the text are included as supplementary material. These supplementary materials will be of particular aid to those looking to develop a basic competency with urban agricultural concepts and stakeholders.

Supplemental Information

Jennifer Cockrell King's Blog: http://foodgirl.squarespace.com/

Food and the City: Interview with Jennifer Cockrall-King:

https://www.youtube.com/watch?v=Jo7WCfgvPsA

Urban Agriculture Meeting Demands in Unlikely Places: Resistance is Fertile Presentation: https://www.youtube.com/watch?v=ZlKdaC4fpNY

Sayre, L., \& Clark, S. (2011). Fields of learning: The student farm movement in North America. Lexington, KY: University Press of Kentucky. xx, 354 pages: ills. ISBN: 9780813133744 Retrieved from http://muse.jhu.edu/book/1980

Serving as part history and part collection of present day case studies, Fields of Learning tells the story of past and ongoing efforts to incorporate land-based learning activities at student farms on college and university campuses across the United States and Canada. Fifteen case studies cover student farms from those with origins in their institutions' agricultural training mission of the 19 th century to present-day programs sprouted from a renewal of interest in food systems. Student farms profiled exhibit both (a) opportunities for educational experience as part of a program by an accredited, degree-granting college or university; and (b) opportunities for students to lead or substantially direct farm activities. Each case study offers insight into the varied paths and practices for successfully creating and maintaining student-run farms as parts of campuses with competing educational priorities, needs for space, and student experiential offerings. The book is concluded with a short chapter of guidelines for starting a student-run farm, with examples drawn from lessons learned in each of the case studies.

Laura Sayre has extensively studied and written on the history of agriculture, especially the transmission of agricultural knowledge, community and collaborative activities in agriculture and the role of agricultural traditions in contemporary agriculture. Her work as part of the Rodale Institute's New Farm, where she compiled a comprehensive database of student farms in North America, forms the basis for her insight into the range of student farms. Dr. Sean Clark provides a case study from his student farm at Berea College, as well as practical guidance for starting and managing a student educational farm in the conclusion.

Fields of Learning will be a useful source of information for anyone involved in decision-making for student-run farms on a college or university campus. A variety of higher education institutions across the United States and Canada from small to large, urban to rural, or public research to private liberal arts are highlighted by the case studies so that any type of college or university considering a student farm will find comparable settings and characterizations. An inventory of student farm projects with data for geographic area, size, products, organic certification, and marketing outlets is included as an appendix and will be helpful for locating nearby or student farms with specific characteristics.

Supplemental Information 
Laura Sayre: http://www.laurasayre.net/

Dr. Sean Clark: https://www.berea.edu/anr/faculty-and-staff/dr-sean-clark/

\section{Designing Spaces for Food}

Both of the books reviewed in this section examine the role of food production in public spaces. University and college campuses are public space for the campus community and often viewed as de facto public spaces by the surrounding communities and stakeholders, especially if they are part of a public institution. The reviewed books offer ideas about how public space for food production has functioned historically, in the present, and might transform in the future.

Nordahl, D. (2014). Public produce: Cultivating our parks, plazas, and streets for healthier cities. Washington: Island Press. xiv, 204 pages: illustrations. ISBN: 9781610915496

Public Produce: Cultivating Our Parks, Plazas, and Streets for Healthier Cities is about putting food at the center of the urban environment. The "public produce" of the title is just that, produce grown on mainly urban public land for the free use by the public. Nordahl ties the idea of "civic agriculture," a system that fosters environmentally, economically, and socially sustainable agriculture focused on local markets and cooperative relationships, to the use of public land to grow food that meets these aims. Nordahl suggests the use of public land for food production and he examines the perceived benefits and challenges in greater detail.

First, Nordahl addresses food security benefits regarding urban agriculture projects on public land, where the increased access to free, local food is seen as a tool to combat food distribution inequities. A look at the socioeconomic and health impacts of inexpensive industrial food versus whole (and often locally grown) food connects ideas about access to greenspace and healthy food options in urban settings to food production as an integral part of public health.

After advocating public produce, Nordahl addresses logistical concerns that those considering implementation of such a project hold. He provides examples of public projects that replace landscape plants with edible plants - pansies for plum tomatoes and grass for greens - on land owned by public institutions and freely accessible to citizens. Each of these examples offer creative ideas that have been successfully implemented with varying degrees of scale, infrastructure, and support. Nordahl also details gleaning (the harvest of excess food from farm fields after clearing for commercial sale) and foraging (the harvest of food from wild or unharvested public sources) projects in urban areas to showcase models for more equitable access to food and community building activities that can arise when groups of people come together to share in food access work.

Lastly, Nordahl highlights how urban agriculture in public spaces functions as an education tool about food production, especially for those that only have little concept of how the food they find in a grocery store is grown. Urban agriculture projects are considered not just as places for food production, but educational spaces where knowledge about food and its impact in the larger society may be taught, discussed, and transformed. 
Darrin Nordahl works in urban design and planning, focused on using agriculture and transportation to transform public spaces and improve quality of life in urban settings. This book is recommended for those that make decisions about the use of land in public spaces, especially land owned by public institutions and governments.

Supplemental Information

Urban Farming Pioneers: Darrin Nordahl promoting Urban Agriculture: https://www.youtube.com/watch?v=aV3IFgCyHmE\&list=PLE4B6106FF2928807\&index=3 Darrin Nordahl: http://darrinnordahl.com/

Parham, S. (2015). Food and urbanism: The convivial city and a sustainable future. London; New York: Bloomsbury Academic. 362 pages: illustrations. ISBN: 9780857854520

In Food and urbanism: the convivial city and a sustainable future, Susan Parham critically explores how food and cities are interconnected at different spatial levels: within private space, as part of urban public space, and at the peri-urban fringes.

The first part of the book explores urban food spaces as part of the home. It focuses on the table as the center of food in our domestic space and extends to the design of the kitchen. It uses historical and sociological context to explore food practices around the table and within the kitchen. This initial section of the book also examines the home garden from the design and siting of gardens as food production spaces to outdoor dining and the use of gardens for food consumption rather than production.

The next section features food and its role in public spaces, from outdoor farmers' markets to street food and restaurant districts. This section also covers the rise of suburban development, and with it, the creation of supermarkets and shopping centers as sources of food, completely distinct from historical paradigms of food access. The history, decline, and recent reemergence of agriculture in urban green space is set into a discussion of changing ideas about land use and food resilience in a modern context.

The last section looks at the periphery of urban areas including impacts on food production resulting from development at the city edge. Strategies such as food and agri-tourism are highlighted as strategies to reduce impacts of urban sprawl. One chapter considers challenges of supporting food space in large urban areas including the emergence of fast food chains, food deserts, and planned (and often gated) communities. Finally, the relation of larger regional food systems to urban food spaces, ties between urban and rural places, and how concepts such as slow food and regional food branding translate to local food systems, serve to unite ideas about food across spatial scales around urban areas.

Food and urbanism: The convivial city and a sustainable future is a dense work of scholarly literature from Dr. Susan Parham at the University of Hertfordshire's Centre for Sustainable Communities in the United Kingdom. Dr. Parham has studied the relation between food and cities since the early 1990s. Her long interest in this topic area has resulted in an extensively researched and comprehensive work on the role of food in urban space. This work is recommended for those that want to deepen their understanding of the historical and social 
context for current urban agriculture activities. An extensive bibliography provides many additional sources of academic research into aspects of food, agriculture, and urban environments.

Supplemental Information

Susan Parham Research Profile: http://vuh-la-risprt.herts.ac.uk/portal/en/persons/susanparham(e4f5a6cb-f918-4754-9305-979fd2f8b8e6).html

TVAD (Theorising Visual Art and Design Research Group) Talk - You're toast! with Dr Susan Parham: https://www.youtube.com/watch?v=SjI9CsA0GCU

\section{Sustainability on Campus}

Sustainability initiatives are often where urban agriculture activities are encouraged and administered on college and university campuses. The books reviewed in this section explore how to lead successful sustainability work across campus-from development projects to classroom courses.

Thomashow, M. (2014). The nine elements of a sustainable campus. Cambridge, MA: MIT Press. xii, 236 pages. ISBN: 9780262321570

Based on the experience from the Thomashow's tenure as a college president, The nine elements of a sustainable campus, provides a model to meld a progressive environment and sustainability ethic with the practical challenges of leading a college. The book is organized into chapters for each of the nine elements: (a) energy; (b) food; (c) materials; (d) governance; (e) investment; (f) wellness; (g) curriculum; (h) interpretation; and (i) aesthetics. A brief history and orientation to the importance and academic thinking on each element is interwoven with anecdotes from the author's own experience to place the reader at the moments when Thomashow recognizes his agency in the sustainable transformation of his institution. Creative suggestions to deal with challenges facing college and university administrators - from how to sustainably deal with deferred maintenance of aging infrastructure to looking at institutional finances through an ecological lens - follows for each of the nine elements. These suggestions are culled from both Thomashow's experience and the creative thinking from innovators in each element topic area.

Thomashow was President of Unity College in Maine from 2006-11, where he lead the transformation of the liberal arts college to a leader in sustainability science as informed by his long professional and personal interest in environmental issues and sustainability. At the writing of the book, Thomashow was leading and consulting on sustainability for colleges and universities across the United States.

Administrators, facility managers, and other involved with the management and planning for university and college campuses may face similar challenges to Thomashow's in conceiving and implementing sustainable strategies to meet the ideal requirements of the students, faculty and staff, alumni, the surrounding community, other stakeholders, and the leaders themselves. His approach that the campus exists at human-scale - the right scale to experiment with and implement sustainability ideas-may encourage creative strategies within and beyond the borders of campus. 
Supplemental Information

Antioch University Environmental Studies Colloquium: The Nine Elements of a Sustainable Campus - Mitch Thomashow: https://www.youtube.com/watch?v=fZ_563Oj2A0

American College \& University Presidents Climate Commitment (ACUPCC) On Air \#1: An Interview with Dr. Mitchell Thomashow: https:/www.youtube.com/watch?v=wIxRk93ZHjA Mitchell Thomashow: http://www.mitchellthomashow.com/

Barlett, P. F., \& Chase, G. W. (Eds.). (2013). Sustainability on campus: Stories and strategies for change. Cambridge, MA: MIT Press. xiv, 319 pages. ISBN: 9780262019491

Editors Peggy Barlett and Geoffrey Chase compiled two dozen case studies on several threads of sustainability at college and universities in the United States. This book traces more than a decade of sustainability work in higher education since their earlier book, Sustainability on campus: stories and strategies for change (Cambridge, MA: MIT Press, (C2004), showcased nascent programs on campuses. This book focuses on leadership and change as a part of each profiled institution's ongoing story. Many of the invited contributors are involved with the Association for the Advancement of Sustainability in Higher Education (AASHE).

Each case study is organized into one of the major themes: (a) Leadership and Commitment; (b) Curricular Transformations; (c) Defining the Paradigm for Change; (d) Institutional Mission and Culture of Sustainability; (e) Accountability; and (f) Professional and Personal Transformation.

In Leadership and Commitment, personal testimonies including Wendy B. Anderson at small liberal arts Drury University, David Whiteman at the urban University of South Carolina, and various faculty at the historically black Florida A\&M University, detail the transformation of themselves and their campuses through sustainability efforts. As a counterpoint, Julie Snow at state college Slippery Rock University bravely details her slow start and failures and well as her eventual successes.

In Curricular Transformations, new focus on local bioregions and global sustainability, and refocus from environment to sustainability, shifts the educational experience to future-facing challenges. William Van Lopik of the College of the Menominee Nation shares how a core course in sustainable development for all students provides education on not only on traditional sustainability topics like recycling or the natural environment, but also personal practices and the sustainable philosophy of the Native American nations and people.

The theme, Defining the Paradigm for Change, explores creative models of organizing campus sustainability work. Staff of the Graham Environmental Sustainability Institute at the University of Michigan-Ann Arbor share initiatives for cross-campus student group coordination, campuswide sustainability assessment, and for-credit, student-instigated sustainability projects. E. Christian Wells of the University of South Florida, reflects on using the metabolic viewthinking of the campus as a living organism with inputs and wastes - in a course project, that later expanded to a greater campus initiative. Kapi'olani Community College professor Krista Hiser uses Brafman and Beckstrom's Spider and Starfish model to describe how their 
decentralized network of faculty functions like a starfish in a non-hierarchical, leaderless model of a collaborative circle.

The Institutional Mission and Culture of Sustainability theme unites multiple narratives from faculty and staff of a range of higher education institutions on their organizational history of sustainability initiatives. Institutions profiled include Spelman College, a historically black college for women, Santa Clara University, a historic Jesuit university, Warren Wilson College, a liberal arts college with service, work and academic requirements for students, Unity College, an experiential learning focused liberal arts college, and Furman University, a southern liberal arts university.

Accountability is represented by a set of projects that use tools such as goals, standards, and administrative structures to demonstrate success of sustainability efforts on campus. Sustainability strategic planning at Yale University keeps sustainability efforts a priority of the administration to meet the goals of the plan as an ongoing effort. Arizona State University and its School of Sustainability tackles building an interdisciplinary degree program and developing core competency for sustainability research and education. The University of Wisconsin Oshkosh shares its commitment to becoming the first U.S. Fair Trade University, integrating its principles into not only campus dining, but curricula and student experiences. Management of some university services at San Diego State University by the Associated Students Council, a student directed board, incorporates student led sustainability initiatives and institutionalized a sustainability advocacy within the organization.

Lastly, the Professional and Personal Transformation section touches on teaching and learning processes that covers sustainability as a new approach to thinking and living. These reflective essays offer innovative methods to share sustainability knowledge. One advocates for reflection and contemplation as a cornerstone of a faculty learning community, which explores how to incorporate these practices into the classroom setting with the goal of deepening understanding. Another reconceives learning as a living system which blurs roles between students and teacher, perception and assumptions, structured and sequenced, and thus the course becomes a series of collective learning experiences rather than self-contained, passive listening events. The last piece looks at teaching as a relationship, with self and with the earth, and developing a set of experiences to explore relationships within and between, therefore changing consciousness about those relationships.

With a wealth of perspectives, settings, and experiences, this book is highly recommended for higher education leaders looking for new strategies and ideas for their own institutions. Anyone interested in the intersection between learning and sustainability will find one of many parts of this book of interest.

\section{Supplemental Information}

Campus Sustainability Month: http://www.aashe.org/campus-sustainability-month/ Sustainability at Emory: Building Community by Going Green (with Peggy Barlett): https://www.youtube.com/watch?v=sxjinY8bqwk

Preparing Students for a Changing Climate (with Geoffrey Chase): https://www.youtube.com/watch?v=0TBy_t0Y4D4 


\section{References}

Brafman, O. \& Beckstrom, R. (2006). The Starfish and the Spider: The Unstoppable Power of Leaderless Organizations. New York: Penguin.

Barlett, P. F., \& Chase, G. W. (Eds.). (2013). Sustainability on campus: Stories and strategies for change. Cambridge, MA: MIT Press.

Cockrall-King, J. (2012). Food and the city: Urban agriculture and the new food revolution. Amherst, NY: Prometheus Books.

Fontaine, M. (2014). Student Relationship Management (SRM) in Higher Education: Addressing the Expectations of an Ever Evolving Demographic and Its Impact on Retention. Journal of Education and Human Development, 3(2), 105-119.

Hedegaard Larsen, M. (2016). Eating the canary in the coalmine: Thoughts and theories to explain the rising importance of food, events and agriculture/place as symbols and media of community and identity in post-modern societies. Berkeley, CA: University of California Berkeley, Institute for the Study of Societal Issues. Retrieved from http://escholarship.org/uc/item/3nw1s6b2

Ladner, P. (2011). The urban food revolution: Changing the way we feed cities. Gabriola Island, B.C.: New Society Publishers.

Nordahl, D. (2014). Public produce: Cultivating our parks, plazas, and streets for healthier cities. Washington: Island Press. https://doi.org/10.5822/978-1-61091-550-2.

Parham, S. (2015). Food and urbanism: The convivial city and a sustainable future. London; New York: Bloomsbury Academic.

Reynolds, K., \& Cohen, N. (2016). Beyond the kale: Urban agriculture and social justice activism in New York City. Athens, GA: University of Georgia Press.

Sayre, L., \& Clark, S. (2011). Fields of learning: The student farm movement in North America. Lexington, KY: University Press of Kentucky. Retrieved from http://muse.jhu.edu/book/1980

Thomashow, M. (2014). The nine elements of a sustainable campus. Cambridge, MA: MIT Press. 


\section{Author Information}

Stephanie Ritchie is the Agriculture and Natural Resources Librarian at the University of Maryland, and previously lead librarian at the Alternative Farming Systems Information Center at the USDA's National Agricultural Library. She has supported researchers in urban agriculture, helped create a USDA urban agriculture toolkit, and currently curates a Mendeley group on the topic available at https://www.mendeley.com/groups/4679531/urban-agriculture/

Stephanie Ritchie, MLS

Agriculture and Natural Resources Librarian

William E. Kirwan Hall Math Building, Room 1403L

4176 Campus Drive

University of Maryland, College Park, MD 20742

E-mail: sritchie@umd.edu

Telephone: 301-405-9153 